\title{
Evolution of Agricultural Support Policy in South Korea
}

\author{
Zheng Gu \\ College of Economics and Management \\ China Agricultural University \\ Beijing, P.R. China \\ guzheng@cau.edu.cn
}

\begin{abstract}
This paper reviewed the key agricultural support policies in South Korea. By using the fundamental definition and assessing method from OECD, the research studied the relation between agricultural support level and the output of agricultural production. The aim of the paper is to discuss the effect of agricultural support policy in South Korea after the World War II and provide policy suggestions for the policy makers.
\end{abstract}

Keywords- Agricultural support; total value of agricultural production; policy; South Korea

\section{INTRODUCTION}

According to the definition from OECD, agricultural support policy (ASP) is the support, subsidy, and assist to agriculture from the government to reduce the production cost and raise the farmers' income. The aim of ASP is to increase the value of agricultural production.

Among agriculture, industry and service sector, agriculture stays at a relative weak status. In the process of industrialization, a country starts to support agriculture to acquire the necessary materials. Capital, raw materials, labor, market and other materials ensure the completion of industrialization. According to the statistic from the World Bank, a national began agricultural support when the GDP per capita reached 1000 US dollars.

In 1960, GDP per capita in South Korea achieved the benchmark and reached 1106 US dollars. Due to the short of historical data from World Bank, the assumption is that South Korea hit the 1000 US dollar level in 1950s. From the independence of Korea in 1948, the government policy began its support to agriculture. In 1967, South Korea launched the Agricultural Basic Law, which represented that the general support to agriculture had begun.

China and South Korea have similar environment for agricultural production. Both countries were invaded by Japan and started recovery after the Second World War. The modern agricultural production and industrialization in South Korea are developed faster than the ones in China. The aim of this research is to understand the evolution of agricultural support policies in South Korea, identify the relation between support levels and the value of production, and then provide reference for agricultural support policy making in China.

\section{METHOD}

There are two popular methods to assess agricultural support level. One is producer support estimate (PSE) by OECD, and the other is aggressive measurement support (AMS) by WTO. Between these two approaches, PSE's coverage is bigger than AMS while the latter only calculates the domestic supports that distort the international trade. This research introduced measurement method by OECD.

\section{A. Classification of ASPS}

OECD classifies the ASPs into three groups, producer support estimate (PSE), customer support estimate (CSE) and general service support estimate (GSSE). PSE calculates the monetary transfer from consumers and tax-payers to producers. It takes the major part of support values and it includes two parts, market price support (MPS) and budget and other transfer (BOT).

MPS includes tariff, import quota, producing quota, administration price and public shareholdings. MPS offers the channel of transfer from consumers to producers. BOT is the all other transfer except MPS, and it provides the route from tax-payers to producers.

\section{B. Calculation of PSE}

As introduced above, PSE is consisted by MPS and BT, and it is the sum of these two indicators.

MPS calculates the support to agricultural producers by monetary value based on years and it sums the support value to individual product. The difference between domestic price which raised by the ASPs and the border price on a certain product multiple the volume of production of this agro product is the support value for this individual unit. MPS is the sum of support value to each individual unit. OECD only calculates 15 types of agro products which covers the majority of food consumption in OECD countries. The types of calculating agro products can be adjusted according to the consumption structure in different countries.

The following formula describes the calculation process for MPS.

$$
\frac{M P S_{C}}{V P_{c}}=\frac{\sum_{i_{\in A M C}} M P S_{i}}{\sum_{i \in A M C} V P_{i}}
$$

MPSc: the total price support in a country; 
VPc: the total value of agricultural production in this country;

$\sum_{\text {ieAMC }}$ MPSi $:$ the sum of market price support on each agro product;

$\sum_{\text {ieAMC }}{ }^{\mathrm{VPi}}$ : the sum of production value of each agro product.

By adjusting the formula, value of MPS can be described as:

$$
M P S_{c}=\frac{\sum_{i \in A M C} M P S_{i}}{\sum_{i \in A M C} V P_{i}} \times V P_{c}
$$

As argued above, BOT calculates the other transfer except MPS. The major parts of BOT have a) the budget transfer to farmers; b) the service for production in farms to farmer; c) the value of general service to collective farmers; and d) transfer from consumers to farmers.

BOT calculates the transfer payment to agricultural producers other than MPS in the all level government administration. It uses the data of real expenses rather than the budget. During the calculation, the overlap part with MPS is reduced.

Thus, PSE can be described as

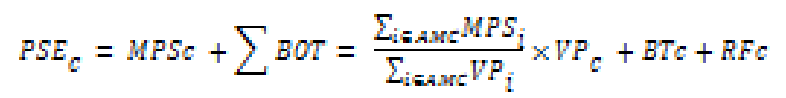

PSEc: the agricultural support estimate for a country; MPSc is the marketing price support value;

BOT is the budget transfer support and other support value; BTc is the budget transfer value; RFc is the support value from revenue free.

\section{THE MAIN ASPS IN SOUTH KOREA}

South Korea developed fast after the World War II and became a developed country. ASPs in South Korea have critical positive effect on eliminate urban-rural income difference, modern agriculture development and complete of industrialization. Since 1948, the ASPs in South Korea can be classified to five stages.

\section{A. Legislation for Agricultural Laws and Regulations}

The first stage was started in 1948, when the new government was established, and finished in 1967. Korea suffered the invade by Japan during the World War II, and there was massive turbulence in politics, economy and society. The priority task of the new government is to recover the economy and ease the high inflation rate. The aim of agricultural policies was to establish modern agricultural administration system. Thus, the Bureau for agricultural development was built up first. Then, in 1949, the South Korea Administration launched the Farmland Reform Bill, to stable the social structure in rural area. The main content of this bill is to abolish the system of landlord and tenant farmers, and develop family farms. From 1950 to 1957, South Korea conducted the land reform. The government bought the farmland from landlords and distributed them to the family farms. Family farm with more than 3 hectares and not-farmers family were not involved in the land reform. In 1961, the government proposed Agricultural Cooperative Law to ensure the growth of agricultural production, and then, in 1967, the South Korea administration promulgated the Agricultural Basic Law, which aimed to guarantee the agricultural producing pattern of family farm unit based.

\section{B. To Promote Agricultural Productivity and Self-sufficient Rate}

The second stage lasted for ten years from 1968 to 1977. In these ten years, the process of industrialization in South Korea accelerated. The manufacturing sector grew fast while agriculture still maintained at a low speed in development. The difference of income between urban and rural areas was enlarged. Due to the growing speed of industrialization and urbanization, farmland was occupied by cities and factories. The area of arable land shrank significantly. Labors in rural area started to transfer to cities. Therefore, the priority aim of ASPs in this stage is to decrease the decline of farm land reducing, promote agricultural productivity, and increase the food volume of production.

To promote the agricultural productivity, the main contents of ASPs in this stage includes: a) Research and promote agricultural technology; b) provide producing technology consultation to producers; c) open up the farmland; d) leveling the farmland; e) develop irrigation system for agriculture; f) promote fine seed; g) promote the agricultural machinery level. Besides, to encourage the farmers to extent farm land area, increase the output of grains and income, from 1970s, the South Korea administration raised the market price for rice and wheat by support policies.

\section{Promote the Comprehensive Development of Agriculture and Increase the Farmers' Income}

South Korea was one of the Four Small Dragons in East Asia, who realized the industrialization by export oriented economy development model. Due to the fast growth for export, the domestic market was ignored. From 1978 to 1985 , low prices for grains by import ceased the development of agriculture, and there were even signs of recession in rural economy. Undeveloped agriculture cannot meet the demand for industrialization. The farmers' income was declining. Labors moved from rural area to the cities and the scale of agriculture shrank. Since 1970s, the food self-sufficient in South Korea dropped significantly. There was constant short supply for agro products. The demanding materials for industrialization, such as cotton, flax, were nearly all depend on import. In 1980, South Korea was attacked by massive cold weather and the rice production declined 36\%. In 1981, 
it started to import rice. In 1984, the beef import was soaring, and caused great impact to domestic beef market and triggered the turbulence of prices for beef. In this stage, frequent fluctuation on the prices for vegetables and animal products deteriorated the rural economy. Debts for farmers were growing and the agro product self-sufficient rate declined. In these circumstances, the South Korea Government launched the Prosper Plan on Agriculture and Fishery.

Meanwhile, the economy policy in South Korea transferred from fast growth to steady growth. The government played less important role in the economy and the market was more opened. The administration on agriculture converted to increase the output of production, market price support and increase farmers' income.

\section{Adjust the Agricultural Producing Structure and Promote the Agricultural Competency}

From 1986 to 1994, South Korea completed its industrialization. Agriculture's weigh in the national economy shrank to a small part and the key target of ASPs was to increase the competency of agriculture.

In 1986, the Uruguay Round of GATT forced South Korea to open its domestic market for agro products. To increase the competency of domestic agriculture to the international market, the government proposed three sets of plan sequentially. In 1989, the Comprehensive Measure to Develop Farming and Fishing Village was launched. This plan aimed establish fund for farm land administration, accelerate the adjustment of structure in agriculture, forest and fishery production; extend non-agricultural incomes; plans for rural residential area; establish agricultural companies; promote agro products and processing companies development; promote agro product export. In 1991, the measure for the Structural Improvement of Farming and Fishing Farming was launched. The plan invested 42 trillion won to promote the living conditions in rural area in 10 year and ensure the growth to competency in agriculture. In 1994, the Agricultural Policy Reform and the Measure for Developing Farming and Fishing Farming was launched. Meanwhile, in the same year, South Korea government started a new Special Rural Developing Tax, which is used to support the adjustment of agricultural structure.

\section{E. Promote the Comprehensive Development in Rural Areas and Increase the Farmer's Income}

In 1995, WTO was formally established and replaced the GATT. To meet the compromise to WTO on the agricultural agreement, South Korea opened up its domestic market gradually. However, the Asian Financial Crisis in 1997 crashed the national economy. In 1998, the prices for agricultural materials soared up in the domestic market and many family farms bankrupted. The environment for rural economy deteriorated suddenly. At this time, the South Korea administration proposed priority developed rural economy and stable the farmers' income policy, and the Special Law for Elimination of Farmer and Fisherman's Debts was launched. The special law reduced the burden for agricultural producers and also extended the deadlines for some debts. In 1998, South Korea accomplished the 42 trillion won investment which proposed in 1992, and decided to invest another 45 trillion won to strengthen the development in agriculture and rural area.

Besides, in 1998, South Korea proposed the Agricultural and Rural Basic Law. The administration of agriculture started the reform. In 2000, the government merged the national agricultural cooperative organization, national livestock cooperative organization, Korea Ginseng cooperative organization, rural development company, water administration organization and farmland improvement cooperative organization to one organization. The integrated organization enhanced the cooperation among farmers, consumers and government. The farmers and consumers can participate to the policy making in the government. After 2000, the government introduced the direct payment policies and began to support household of environmental friendly type. In 2004, South Korea launched the Special Law for Farmers' Living Quality Improvement and Rural, Forest, Fishery Development Promotion. Based on the special law, the administration proposed Agricultural and Rural Community Comprehensive Plan and Framework for Agricultural and Rural Community 10 Year Policy. The government made policy roadmap for policies on food price, agriculture, rural area and development, to realize the agricultural and rural community comprehensive plan. Besides, the government decided to invest 119 trillion won from 2004 to 2013 to agriculture to ensure the plan was implemented.

\section{THE EFFECT OF ASPS IN SOUTH KOREA}

To examine the effect of ASPs in South Korea, this research compared the PSE value and total value of production from OECD to identify the relation between these two indicators. Meanwhile, GDP per capita is used to reflect the relation of support levels and economy development. The data of GDP per capita is drawn from the World Bank. Data period is from 1986 to 2012, which is the assessable official data from OECD. As shown in Figure 1, the black curve represents the GDP per capita. Dotted line with square markers is the total value of production while the dotted line with triangle markers is PSE in South Korea. By comparing the three curves, the analysis can be summarized as follows.

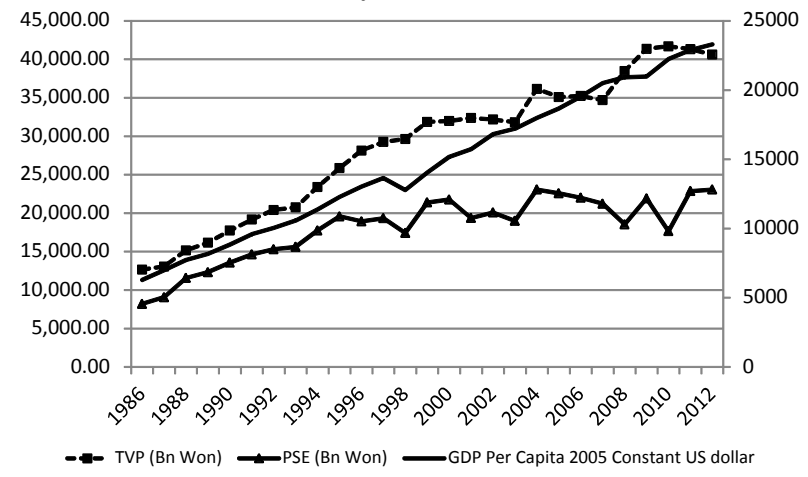

Figure 1. Trends of ASP Levels, TVP and GDP per Captia 


\section{A. The General Trends of PSE Increased Along with Economy Growth}

As shown in Figure 1, the general trend of PSE increased from 1986 to 2012. However, the growing speed was various during these years.

From 1986 to 1994, it showed a rapid growth which the increasing speed was similar as the growth of GDP per capita. Meanwhile, the growing speed of TVP showed the same trend as the other two indicators. The output of agriculture, or the effect of ASPs, was positive during these years.

After 1995, the year of establish of WTO, GDP per capita and TVP kept the growing speed while PSE growth began to slow down and maintained at a relative stable level with minor increase until 2012. Though there were fluctuations for the past years, the general level of support was limited by the compromise to WTO. During the fluctuations, the PSE value in 1998, 2008 and 2011 hit the low points. As analyzed in previous section, South Korea suffered the Asian Financial Crisis in 1998 and the support level to agriculture shank significantly due to the limit government budget.

The reason for lowest points in 2008 and 2011 were partly due to the sub-loan crisis but were mainly because the soaring prices in the international food market. As shown in Figure 2, international food prices reached the peak in 2008 and 2011 respectively. Agricultural producers gained benefit from the high price in the world market and depend less on the domestic agricultural support policies to ensure their incomes. High food price lead the transfer to farmers from consumers rather than the tax-payers.

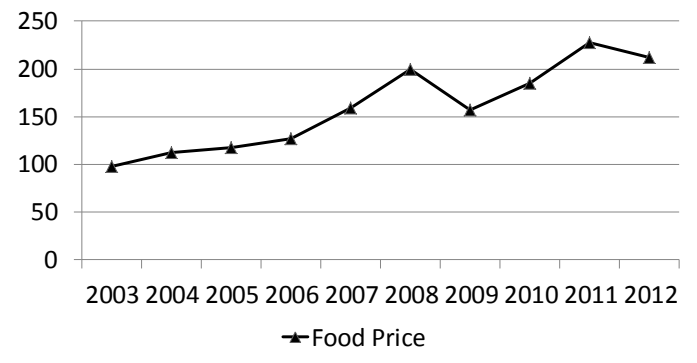

Figure 2. Changes of International Food Price

\section{B. The Trends of TVP and PSE were Similar but the former TVP Grew Faster than the Latter}

The curves in Figure 1 proved the fundamental view point of development economic that agriculture needs more and more support along with the growth of economy. However, the growth of PSE cannot catch up with the growth of TVP. The gap between TVP and PSE enlarged in recent years. From 2008 to 2012, the TVP value maintained at the same level and showed a modest trend of decline. The output of agriculture benefited not enough from the support levels.

\section{The WTO Rules Held the Speed of PSE Growth}

Since 1995, the year of WTO establishment, PSE value cannot increase freely due to the compromise in the agricultural agreement. Meanwhile, among OECD countries, the \%PSE of South Korea is much higher than the average level. The \%PSE in 2012 in South Korea was around 50\% and the average value in OECD was 19\%. PSE methods cause distortion to agricultural international trade and the general trend will be force to reduce in the following years.

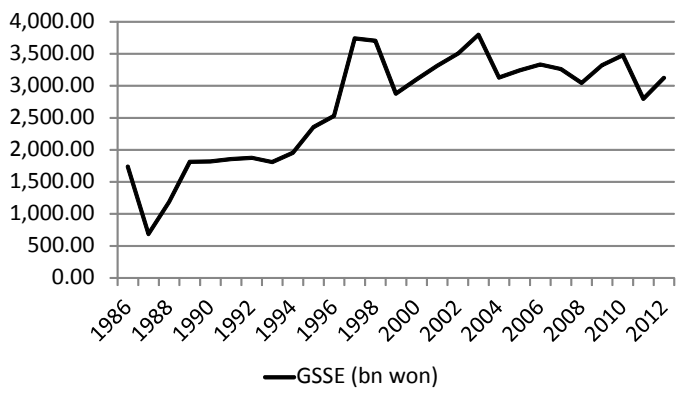

Figure 3. GSSE Level in South Korea

Developed countries are converting their PSE methods to GSSE methods, which can increase the competency of agriculture and also do not distort international trades. As shown in Figure 3, GSSE kept the similar trend with PSE. However, after 1995, the overall level of GSSE was not increased. Slow growth of PSE and GSSE were the key reason for declining of TVP in recent years.

\section{POLICY RECOMMENDATION}

Oriented from the analyzing result to South Korea, the recommendation for future China ASP policies are proposed.

\section{A. Promote the Level of ASPs to Ensure the Output of Agricultural Production}

The average PSE level or GSSE level in China is quite low, especially due to the large population. The compromise support level to WTO by China on Agricultural agreement is $8.5 \%$ of the total value of production. The current support level is far below the limit.

China has already stepped into the middle stage of industrialization. Rapid increase on agricultural support will ensure the satisfied amount of agricultural output and support the national economy complete the process of industrialization. Meanwhile, modern agriculture could be a growing point in economy and avoid to be trapped in middle -income countries.

\section{B. Convert to GSSE Methods to Avoid Reduction of PSE in the Long Term}

Although the current support level in China has not reached the limit by WTO, the South Korea experience showed that the reduction of PSE and convert to GSSE need a long time and had negative influence on the total value of production. 
OECD measurement over valued China's support levels because the weight of self-consumed agro products in China's rural areas. China is still a developing country and the rural economy has the feature of self-supplied rather than sell all of the products in the market. PSE by OECD is proposed based on the economy in developed countries and it over valued the support in China. Despite this factor, in 2012, \%PSE in China was $15 \%$, which was approaching the average level $19 \%$ in OECD countries.

Thus, from the long term perspective, ASPs in China should focus more on GSSE methods rather than the PSE ones. Gathering the limited financial budget to GSSE support can optimize the support structure to agriculture and increase its competency in the international market, then realize the consistent development of modern agriculture.

\section{Launch ASPs in the Pattern of Laws}

The government administration system in China is large and complicated. The rent seeking phenomenon still exists in different level of the system. The effect of policies is reduced during the process of implementation.

South Korea's ASPs system are mainly combined by two parts, basic law and plans associated with the basic law. China can learn this pattern and launches policies by law. Meanwhile, the laws should be accompanied with reasonable budget to ensure the implementation. This may increase the efficiency of ASPs implementation and reduce the waste for valuable budget resources.

\section{Accelerate the Process of Urbanization}

Unlike South Korea, rural population in China is large and it drew back the average support to each household. The central government in China proposed the guidance for industrialization, urbanization and agriculture modernization.

Proposed suitable polices and race up the process of urbanization can reduce the population in the rural area, which will help to increase the average support value to each farmer or household.

\section{E. Build Up Suitable Evaluation Systems for ASPs to China}

OECD's assessment is designed based on developed economies and overvalued China's support levels. As discussed previously, China is still a developing country and the financial budget is limited. Short of support to agriculture will result in insufficient output from agriculture and over support will cause producer's unnecessary reply on the policies and reduce the agriculture competency in the international market. Thus, a reasonable and suitable evaluation system which can reflect the rural economy features in China should be proposed. It will help the policy makers understand and decide adequate support levels more precisely.

\section{REFERENCES}

[1] Timmer, C.P., A world without agriculture: The structural transformation in historical perspective. 2009: Aei Press. pp. 92.

[2] Godo, Y. Evaluation of Japanese Agricultural Policy Reforms under the WTO Agreement on Agriculture. 2012 Conference, August 18-24, 2012, Foz do Iguacu, Brazil. 2012: International Association of Agricultural Economists.

[3] Beghin, John C., Jean-Christophe Bureau, and Sung Joon Park. "Food security and agricultural protection in South Korea." American Journal of Agricultural Economics 85.3, 2003, pp 618-632.

[4] Wade, Robert. "Irrigation and agricultural politics in South Korea." Irrigation and agricultural politics in South Korea, 1982.

[5] Boestel, Joanna, Penelope Francks, and Choo Hyop Kim. Agriculture and economic development in East Asia: from growth to protectionism in Japan, Korea and Taiwan. Routledge, 2013.

[6] Cha, Eun Shil, Mihye Jeong, and Won Jin Lee. "Agricultural pesticide usage and prioritization in South Korea." Journal of agromedicine 19.3, 2014, pp281-293.

[7] Jensen, Henning Tarp, Sherman Robinson, and Finn Tarp. "Measuring agricultural policy bias: General equilibrium analysis of fifteen developing countries." American Journal of Agricultural Economics 92.4, 2010, pp1136-1148.

[8] Diakosavvas, D., How to measure the level of agricultural support: Comparison of the methodologies applied by OECD and WTO. Agricultural policies in China after WTO accession, 2002: pp. 217245.

[9] Anderson, K., Distortions to agricultural incentives: A global perspective, 1955-2007, World Bank Publications, 2009, pp 12-22

[10] Anderson, K. \& Martin, W., Distortions to agricultural incentives in Asia, World Bank Publications, 2009, pp 75-91

[11] OECD, Introduction to the OECD Producer Support Estimate and Related Indicators of Agricultural Support. OECD Observer. OECD, 2010

[12] Tian, W., Zhang, L. \& Zhou, Z., Experiences and issues in measuring the level of support in China. IN OECD (Ed.) Agricultural policies in China after WTO accession Paris, OECD, 2002

[13] Todaro, M. P. \& Smith, S. C. Economic development, Boston, Pearson Addison Wesley, 2009

[14] Wu, L. Selected Cases of Macroeconomics Beijing, China RenminUniversity Press, 2013, pp121 